\title{
Erratum: Burnout, employee engagement and self-perceived employability in the South African public sector
}

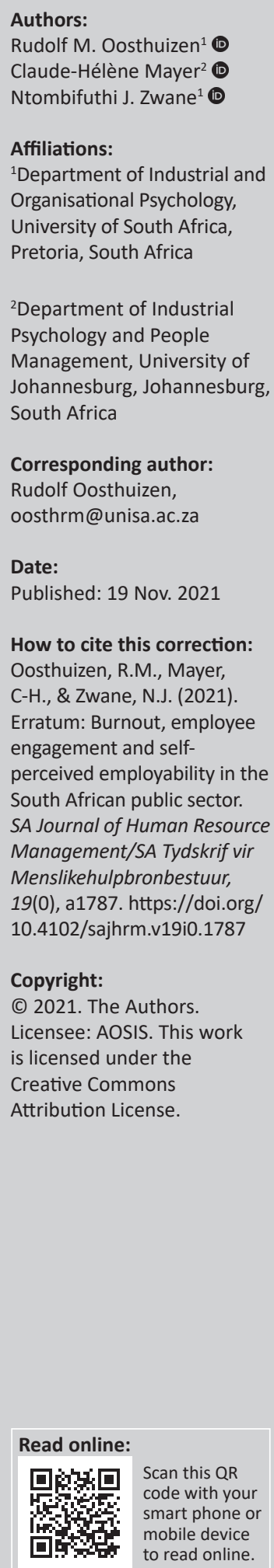

In the published article, Oosthuizen, R.M., Mayer, C-H., \& Zwane, N.J. (2021). Burnout, employee engagement and self-perceived employability in the South African public sector. SA Journal of Human Resource Management/SA Tydskrif vir Menslikehulpbronbestuur, 19(0), a1340. https://doi. org/10.4102/sajhrm.v19i0.1340, there was an error in the affiliation for the second author. Instead of 'Department of Industrial and Organisational Psychology, University of South Africa, Pretoria, South Africa', it should be 'Department of Industrial Psychology and People Management, University of Johannesburg, Johannesburg, South Africa'. The publisher apologise for this error.

The correction does not change the study's findings of significance or overall interpretation of the study's results or the scientific conclusions of the article in any way. 


\section{Burnout, employee engagement and self-perceived employability in the South African public sector}

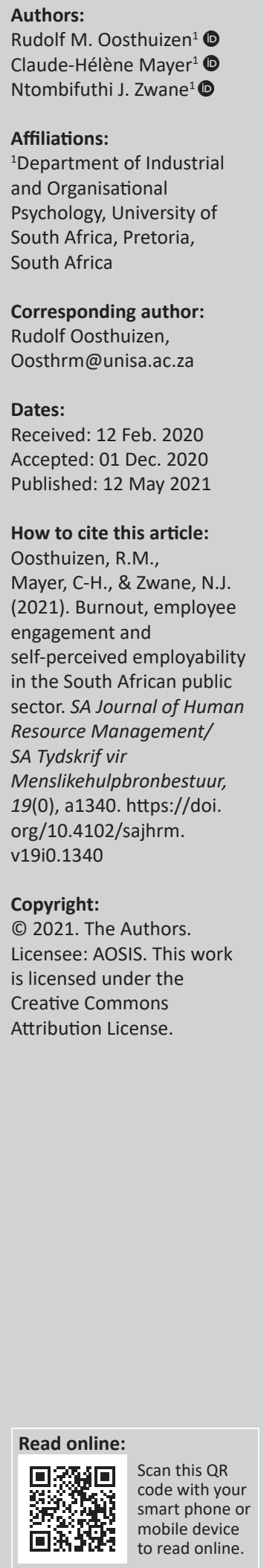

Orientation: The employee engagement (EE) approach has been utilised to combat burnout (BO) in both private and public sector institutions. With increasing research, self-perceived employability (SPE) is gaining popularity as an effective tool for reducing BO. Knowledge of the relationship between these three constructs is therefore important for public sector institutions and researchers in Industrial and Organisational (I/O) Psychology and human resource management (HRM) in South Africa.

Research purpose: The purpose of this study was to determine the relationship between BO, EE and SPE amongst employees in South Africa's public sector.

Motivation for the study: Numerous studies have highlighted the prevalence of poor service delivery in public sector institutions in connection with $\mathrm{BO}$ and highlighted a decrease in $\mathrm{BO}$ through EE and SPE. However, the relationship between these three constructs is still quite unknown. The study's results will fill the void of research in this area and can be applied in I/O Psychology and HR practices.

Research design, approach and method: This quantitative study involved a non-probability sample of 158 South African public sector employees. Correlational and descriptive statistical analyses were used to analyse the data.

Main results: Burnout has a significant negative relationship with EE; however, BO does not significantly correlate with SPE. There are significant differences between the various biographical groups and $\mathrm{BO}, \mathrm{EE}$ and SPE.

Practical/managerial implications: Approaches to reducing $\mathrm{BO}$ amongst employees should consider EE and SPE as effective tools to enhance employees' wellness, morale and improved service delivery.

Contribution/value-add: Improving the EE levels and enhancing SPE will improve the well-being of employees in public sector institutions and help alleviate employee BO.

Keywords: burnout; employee engagement; self-perceived employability; public sector; non-human services sector.

\section{Introduction}

The promotion of employee health and wellness in organisations is regarded as a crucial factor for organisational success. Organisations have attempted to improve employee health and well-being and to advance human potential (Usman \& Raja, 2013; Van den Broeck, Vansteenkiste, De Witte, \& Lens, 2008). Evidence of this is demonstrated through the programmatic interventions in the workplace such as wellness programmes aimed at promoting the well-being of employees (Mattke et al., 2013). This demonstrates the constant interventions implemented by organisations to address psychosocial stressors which will enhance employees' health, wellness and morale. A practical example of this is in South African public sector institutions (Department of Public Service and Administration [DPSA], 2015, 2016).

However, larger numbers of employees around the world, from both private and public sectors, for example, the United States of America, Canada, Taiwan, Japan, Ghana and South Africa, still suffer from numerous stressors. This may cause employees to experience certain levels of burnout (BO) (Hirayama \& Fernando, 2016; Lindén, Salo, \& Jansson, 2016; Palazzo, Carlotto, \& Aerts, 2012; Schaufeli, Leiter, \& Maslach, 2009). The literature shows that a myriad of BO experiences in public sector institutions encompass employees feeling unvalued, chronic fatigue and feeling disconnected from the objectives of their public institutions (Bell \& Bell, 2010). These experiences are associated with their unsuccessful attempts at improving the quality of services because of the lack of available resources (Hirayama \& Fernando, 2016). 
Engaged employees are more productive, more committed and more likely to remain with their employer (Gupta \& Sharma, 2016; Kosuta, 2010; Moodley, 2010; Vigoda-Gadot, Eldor, \& Schohat, 2012). They have a sense of energy, close involvement with their job and the ability to deal well with the demands of their job (Schaufeli, Taris, \& Van Rhenen, 2008). In addition, engaged employees perceive themselves as being in control and perceive the workload as sustainable. This is directly the opposite of $\mathrm{BO}$, of having no control and perceiving an excessive and unattainable workload (Moodley, 2010). In this context, self-perceived employability (SPE) refers to individuals' self-perception of their capabilities of obtaining and retaining fulfilling work and having the knowledge, understanding, skills, experience and personal attributes to move self-sufficiently within the labour smarket (Coetzee, Roythorne-Jacobs, \& Mensele, 2016). As a result, there has been a focus on new mechanisms to address employees' psychosocial stressors such as focusing on psychosocial meta-capacities of employability (Coetzee et al., 2016).

This study focuses on the relationship between BO, employee engagement and SPE to fill the void in theory regarding the South African public sector. Public sector employees in the contemporary global economy are faced with a myriad of psychosocial stressors because of high job demands (Schaufeli $\&$ Taris, 2014) as well as changes in psychological contracts (Coetzee et al., 2016). These institutions are promoting employee health and commitment (Usman \& Raja, 2013) to achieve service delivery. However, research shows that public sector employees are increasingly experiencing numerous stressors and various levels of BO (Palazzo, Carlotto, \& Aerts, 2012).

Several approaches on combating experiences of $\mathrm{BO}$ have been realised in the world of work, such as EE and SPE. Traditionally, EE has been utilised as a tool to reduce BO (Maslach \& Leiter, 2016), as well as to achieve competitive advantage for both individuals and organisations (Nienaber \& Martins, 2015). Even with such measures in place, research still indicates high BO experiences amongst public sector employees because of changes within the global economy (Guan et al., 2017). Employees focus on increasing their employability by taking charge of their careers to survive the situation. In South Africa, they tend to be perceived with a lack of growth and career path (Bosman, Rothmann, \& Buitendach, 2005), thus resulting in employees feeling frustrated, stressed and demotivated (Vanhercke, De Cuyper, \& De Witte, 2016). It is therefore prudent to investigate the relationship between BO, EE and SPE within South Africa's public sector.

Existing research refers to the relationship between $\mathrm{BO}$ and EE within the South African public sector, drawing specifically on police, healthcare and social welfare institutions (Schaufeli et al., 2009). Limited studies focus on BO beyond the human services occupations. This study explores a South African public sector institution with a core mandate beyond the human services occupations.

\section{Literature review}

Numerous studies have been conducted on the relationship between $\mathrm{BO}$ and EE within the South African public sector (Schaufeli et al., 2009). Most of these studies stem from stressful work environments that are related to human services such as the police, healthcare and social welfare (Schaufeli et al., 2009). Limited studies were conducted in the South African context with a focus beyond the human services occupations, such as managers and white-collar employees. This research focused on a South African public sector institution that has a core mandate beyond the human services occupations.

Furthermore, EE has been used as an intervention to erode $\mathrm{BO}$ amongst employees in organisations for over two decades now. Yet, employees currently experience high levels of BO in the workplace. Current literature has considered the postmodern, workplace environment of the 21st century, and newly emerged constructs such as SPE have gained significant popularity in the literature as important and relevant coping resource mechanisms (Van der Vaart, 2012). However, fewer studies have looked at the relationship between EE and SPE in terms of how they relate to each other. In addition, there are hardly any studies that investigated SPE as a psychosocial resource mechanism for the issues of BO and EE. There is, therefore, a lack of, or an absence of studies that investigated the relationship between BO, EE and SPE amongst employees in the South African public sector.

\section{Burnout}

Burnout is a prolonged response to chronic interpersonal stressors on the job (Maslach \& Leiter, 2016). It is associated with emotional exhaustion (EX), depersonalisation and reduced personal accomplishment that can occur amongst various professionals (Maslach \& Leiter, 2016). Public sector employees in South Africa do experience symptoms of BO (Lehohla, 2016). Several factors contributing to BO have been identified, such as low self-esteem or low confidence (Maslach, Schaufeli, \& Leiter, 2001); a high workload and lack of resources (De Villiers \& Hsiao, 2017; Schaufeli et al., 2009).

Public sector employees in South Africa's government tend to be affected by these factors, making them susceptible to BO. They further feel uncertain about their growth and career path (Bosman et al., 2005), and experience symptoms of BO because of high job demands and lack of job resources (Fragoso et al., 2016). Since the 1990s, research focuses on positive aspects that impact positively on $\mathrm{BO}$ and has since then focused on EE as a strategy to deal with BO (Rothmann \& Rothmann, 2010; Schaufeli et al., 2009; Schaufeli \& Taris, 2014).

\section{Employee engagement}

Research on EE includes aspects of work and personal engagement, studying EE on an individual and organisational level, and defining it as enthusiasm for work and taking positive action to further the organisation's reputation and 
interests (Nienaber \& Martins, 2015). Employee engagement is associated with emotionally and intellectually engaged employees who are attached and committed to the organisation's goals and its values (Rajani \& Joshua, 2016).

Employee engagement is utilised in public sector institutions as a mechanism to attain positive outcomes for both the individual and the organisation (Martins, 2015). Numerous institutions have adopted this approach to combat BO and achieve optimal work performance (Vigoda-Gadot et al., 2012). However, the literature indicates that public sector employees still face a myriad of BO experiences (Guan et al., 2017). These experiences include feeling unvalued, chronic fatigue and feeling disconnected from the objectives of their public institutions (Bell \& Bell, 2010). Researchers have explored other interventions of dealing with BO issues such as EE and SPE (Lu, Sun, \& Du, 2016; Qenani, MacDougall, \& Sexton, 2014); however they were not in the South African context.

\section{Self-perceived employability}

Self-perceived employability refers to an individual's perception of his or her capabilities of obtaining and retaining fulfilling work and having the knowledge, understanding, skills, experience and personal attributes to move self-sufficiently within the labour market (Coetzee et al., 2016). It is associated with the individual's perception of being employable, in control of his or her career and being independent. Subsequently, it may result in improved job performance, resilience, successful careers, as well as better health and life satisfaction (Qenani et al., 2014). Individuals, who perceive themselves as employable, tend to be proactive, accountable and continuously advance their knowledge and skills for career progression (Coetzee, Oosthuizen, \& Stoltz, 2015).

Recent studies have found evidence of the negative relationship between BO and SPE (Lu et al., 2016). The trend is that individuals who self-perceive the inability to advance their employability skills over time are likely to continuously feel stressed, and they eventually experience BO (Lu et al., 2016). Self-perceived employability is seen as an internal resource that can protect individuals from stressful work environments (Lu et al., 2016). There has been no investigation into the relationship between $\mathrm{BO}, \mathrm{EE}$ and SPE so far.

\section{Research objective and value-add}

The objective of this study was to determine the relationship between BO, EE and SPE amongst employees in the South African public sector. As highlighted, knowledge of the relationship between $\mathrm{BO}, \mathrm{EE}$ and $\mathrm{SPE}$ is important for public sector institutions in South Africa to combat BO through a positive behaviour approach. This study adds to the body of research and knowledge of Industrial and Organisational (I/O) psychologists and human resource management (HRM) in conceptualising the factors moderating BO, EE and
SPE. Knowledge of the nature and relationships between these constructs will enable researchers to provide valuable information and insight; diagnose and solve problems to improve the well-being of employees and work performance and reduce $\mathrm{BO}$ and its symptoms in employees.

\section{Research methodology}

This study adopted a quantitative approach using a survey design. Three key variables were identified for this study, namely public sector employees' experience of BO, EE and perceived employability. The empirical relationship between these constructs was investigated by means of correlational statistical analysis, using the Pearson correlation $(r)$. All instruments utilised were standardised instruments and the sample was representative.

\section{Research participants}

The study sample consisted of 158 participants. The population constituted permanently employed public sector employees in a non-human services government institution. A non-probability approach, using a convenience sampling method, was applied. Most of the participants were African (75\%) followed by white participants $(25 \%)$. The African group included black (70\%), coloured (4\%) and Indian (1\%) races. Fifty five per cent of the participants were married and $45.93 \%$ were unmarried, which comprised single, divorced and widowed participants. In terms of qualifications, most of the participants $(58 \%)$ had obtained an undergraduate qualification, followed by $32 \%$ who had obtained a postgraduate qualification. The smallest group had obtained a matric qualification (10\%). Most of the participants were older than 35 years $(73.4 \%$ ) with the mean age being 42 years (Standard deviation $[\mathrm{SD}]=8.82$ ). Most participants had more than 10 years' experience and $38.60 \%$ of the participants had less than 10 years' work experience. The mean tenure was 15 years $(\mathrm{SD}=10.3)$.

\section{Measuring instruments}

Data was collected by using a biographical questionnaire, the Maslach BO Inventory (MBI-SS); the EE Dimensions scale (employee engagement instrument [EEI]) and the Employability Attributes Scale (EAS).

\section{Biographical questionnaire}

A biographical questionnaire was used to gather the biographical data of the participants such as age, gender, race, qualification, home language and marital status. The questionnaire comprised a set of multiple-choice options, where the respondents ticked the boxes pertaining to them. The biographical data provided a valuable analysis of $\mathrm{BO}, \mathrm{EE}$ and SPE amongst the various biographical groups.

\section{The Maslach burnout inventory}

The MBI-SS consists of 16 items that constitute three scales, namely exhaustion (EX; five items), cynicism (CY; five items), and efficacy (EF; six items). All these items were rated on a 
seven-point rating scale starting from zero (never) to six (always). High scores on EX and CY and low scores on EF indicate $\mathrm{BO}$ (i.e. all EF items are reverse scored, which is denoted by $\mathrm{rEF}$ ). The MBI-SS meets the psychometric properties of validity (construct) and reliability (Storm \& Rothmann, 2003). For the present study, Cronbach's alpha coefficients for the overall MBI-SS are greater or equal to 0.70 . The Cronbach's alpha coefficients of the MBI dimensions were $\mathrm{EX}=0.85 ; \mathrm{CY}=0.73$; and professional $\mathrm{EF}=0.76$.

\section{The employee engagement instrument}

The EEI of 50 items consisted of six subscales, namely customer service (six items), immediate manager (seven items), organisational commitment (six items), organisational satisfaction (nine items), strategy implementation (10 items) and team (12 items). The EEI was rated on a five-point Likert scale: 1 for strongly disagree; 2 for disagree; 3 for unsure; 4 for agree; 5 for strongly agree. A study by Martins and Ledimo (2016) confirmed the validity and reliability of the EE questionnaire for government institutions. The reliability coefficients of internal consistency, Cronbach's alpha coefficients, ranged between 0.816 and 0.946 (Martins \& Ledimo, 2016). Cronbach's alpha coefficients of EEI and their dimensions for the present study ranged from 0.82 to 0.96 .

\section{The employability attributes scale}

The EAS of 56 items constitutes eight subscales, namely career self-management (11 items), cultural competence (five items), self-efficacy (six items), career resilience (six items), sociability (seven items), entrepreneurial orientation (seven items), proactivity (seven items) and emotional literacy (seven items). High scores represent more perceived employability by the participants. According to Potgieter and Coetzee (2013), the EAS scale meets the psychometric properties of validity (construct) and reliability. The reliability coefficients of internal consistency, Cronbach's alpha coefficients, range between 0.78 and 0.90 for each subscale (Potgieter \& Coetzee, 2013). For this study, Cronbach's alpha coefficients for the EAS and its sub-dimensions were therefore acceptable as they were within the range of 0.78 and 0.90 .

\section{Research procedure and ethical considerations}

The questionnaires were manually distributed to the participants. The informed consent form explained to the participants the purpose of the research, procedure, potential benefits, confidentiality, anonymity, voluntary participation, withdrawal and their rights regarding participating in the study. All participants willingly signed the informed consent form and participation was voluntary. The study used convenience sampling (Raju \& Prabhu, 2019) for the data collection. The questionnaires were hand delivered to the participants' offices. To ensure the honesty and integrity of the results, the participants were given ample time to complete the questionnaire and the researcher was available for any questions. Completed questionnaires were kept secure, and the raw data was captured and converted to the
Statistical Package for Social Sciences (SPSS), version 25 dataset.

\section{Validity and reliability}

To ensure validity, standardised measuring instruments, appropriate data analysis techniques, models and theories relevant to the research were utilised. In addition, a representative sample was utilised to obtain an internal validity of the research findings. The following measures were taken to ensure the validity of this study: (1) effective planning and structure of the research design to ensure the validity of the research findings, (2) the use of models and theories relevant to the research topic, aim and problem statement, (3) ensuring that the selected constructs were valid, appropriate and applicable, (4) selecting accurate, appropriate and applicable measuring instruments, (5) selecting a representative sample to ensure external validity, (6) collecting, storing and analysing data electronically, (7) ensuring data authenticity by means of encryption and password protection, and (8) conducting appropriate and accurate data analysis.

To ensure reliability, all instruments utilised were standardised instruments. The data was collected from only the South African public sector employees in a non-human services public sector organisation. The data analysis was conducted by using the SPSS Software program version 25.0. To ensure the reliability of the measure, Cronbach's alpha coefficient (reliability analysis) was also computed. In terms of the research process, the following control mechanisms were implemented to ensure reliability: (1) the three measuring instruments used to collect data complied with stringent validity and reliability requirements; (2) only employees from the non-human services public sector institution were invited to participate; (3) all data collected was stored electronically by the administrator and access to this information was restricted to the researchers; (4) reliability in the analysis was ensured by the use of statistical packages (Statistical Package for the Social Sciences [SPSS] \& Statistical Analysis System [SAS]) to analyse the data, and (5) Cronbach's alpha coefficients were used to establish internal consistency and resultant reliabilities of the instruments used to collect data.

\section{Statistical analysis}

The data was analysed with the SPSS, version 25.0. Descriptive statistics were computed to describe the data in terms of sample composition and average scores on the BO inventory, the EE measurement, and the EAS by using frequencies, means, and SDs. Correlational analysis was computed with the Pearson correlation $(r)$ to determine the strength of the relationships in terms of BO, EE and SPE, as well as to determine the correlation between demographic variables and BO, EE and SPE (Levin, Szabat, \& Stephen, 2016). Multiple regression analysis was used to determine the relationship between $\mathrm{EE}$ and SPE on BO. In terms of the significant value, the confidence interval level at $95 \% \quad(p \leq 0.05)$ was deemed to be statistically significant (Cohen, 1992). Since the data was normally 
distributed, the $t$-test for independent samples and analysis of variance (ANOVA) were performed to determine the differences between groups.

\section{Ethical consideration}

The researchers obtained ethical clearance from the University's Ethics Review Committee (RERC) to conduct the study. The researchers also obtained permission to collect data from the management of the organisation in which the current study was conducted.

\section{Results \\ Descriptive statistics}

The mean scores for the MBI-SS (BO), EEI (EE) and EAS (SPE) ranged between 3.25 and 4.61. The participants obtained a higher mean score on EAS $(M=4.61)$, which could indicate that they perceived themselves as employable. The scores obtained on EEI $(M=3.48$; $\mathrm{SD}=0.64)$ were at a moderate level, which could indicate that the participants agreed with the EEI items to a reasonably fair extent, and therefore felt more or less engaged in their work. The participants obtained lower mean scores on $\mathrm{BO}(M=3.25$; $\mathrm{SD}=0.77)$, which are indicative of less $\mathrm{BO}$.

\section{Burnout (Maslach burnout inventory)}

The participants scored higher on professional EF $(M=3.25)$, which indicates their positive feelings about their work and feelings of competence. The participants scored lower on EX $(M=2.46 ; \mathrm{SD}=1.50)$ and $\mathrm{CY}(M=2.10 ; \mathrm{SD}=1.29)$, thus indicating that the participants rarely felt emotionally drained and did not experience negative and impersonal attitudes and feelings towards other people. With regard to the skew, all the scales scored between 0.14 and 0.68 , thus showing that the distribution is moderately skewed right. In terms of kurtosis, all the scores except for professional EF, scored between -0.55 and -0.01 , representing a light-tailed distribution (Howell, 2004).

\section{Employee engagement (employee engagement instrument)}

In terms of the means, the participants scored higher means on team $M=3.9 ; \mathrm{SD}=0.73$ and on organisational commitment $M=3.75 ; \mathrm{SD}=0.77$. This shows that the participants could effectively engage in teams and that they were committed to their organisation. The participants obtained moderate scores on customer service $(M=3.36$; SD $=0.79)$, immediate manager $(M=3.46 ; \mathrm{SD}=0.98)$ and organisational satisfaction $(M=3.47 ; \mathrm{SD}=0.85)$ variables. Lower mean scores were obtained on strategy and implementation $(M=2.89 ; \mathrm{SD}=$ 0.88). It is clear from the results that most of the participants agreed with the EEI items, indicating they were feeling engaged with their work at a moderate level. The distribution is skewed to the left. All the scores on skew are between -1.5 and -0.08 , thus showing that the distribution is moderately skewed left (Howell, 2004). In terms of the kurtosis, for the overall EEI instrument kurtosis, 0.84 indicates that the distribution is moderately skewed left, with the kurtosis sample score closer to zero, taking the shape of a normal distribution.

\section{Self-perceived employability (employability attributes scale)}

The participants obtained a higher mean on self-efficacy $(M=4.78 ; \mathrm{SD}=0.69)$ and a relatively lower mean on the subscale sociability $(M=4.27 ; \mathrm{SD}=0.86)$. These scores indicate that the participants perceived themselves as employable. They saw themselves as capable of retaining and fulfilling their work (Coetzee et al., 2016) as well as being in control of their careers. The skew for the EAS scale and subscales is negatively skewed and has coefficients ranging between -0.07 and -0.47 . These coefficients fall within the normality recommended range of -1 and +1 (Howell, 2004). The kurtosis values ranged between -0.15 and 0.11 , and since the scores are closer to zero, the shape of a normal distribution is reflected.

\section{Correlation analysis between burnout, employee engagement and self-perceived employability}

Table 1 indicates the existence of a significant negative correlation between $\mathrm{BO}$ and each of its dimensions (EX, CY and professional EF) and against EE and its dimensions (customer service, immediate manager, organisational commitment, organisational satisfaction, strategy implementation). The correlation coefficients between $\mathrm{BO}$ and its dimensions and against $\mathrm{EE}$ and its dimensions are all negative and they vary from $r=-0.24$ (negative medium effect size), to $r=-0.67$ (negative large effect size) at $p \leq 0.05$. Numerous studies identify EE as crucial for building modern public sectors and promoting the well-being of employees in government institutions (Martins \& Ledimo, 2016; Vigoda-Gadot et al., 2012). Therefore, the results of this study confirm this notion and support the stance that EE can be utilised in the South African public sector to reduce BO. This study, therefore, considers EE as an effective tool to approach the challenges related to $\mathrm{BO}$ amongst public sector employees to enhance service in public sector organisations.

Table 2 shows the correlation between $\mathrm{BO}$ and SPE. The relationship between the overall $\mathrm{BO}$ and the overall employability is negative ( $r=-0.79$; negative large effect size); however, it is not statistically significant $(p \leq 0.32)$. The strongest correlations were observed between professional EF (reverse coded), which significantly correlated with the following employability dimensions: with career self-management $(p \leq 0.025)$, career resilience $(p \leq 0.0529)$, sociability $(p \leq 0.0038)$, proactivity $(p \leq 0.0118)$, emotional literacy $(p \leq 0.029)$ and the overall employability variable $(p \leq 0.017)$. The correlations vary from $r=-0.15$ (negative small effect size) to $r=-0.23$ (negative small effect size). However, previous research shows that SPE is a psychosocial meta-capacity or new mechanism for addressing employees' psychosocial stressors 
TABLE 1: Correlations between subscales of employee engagement and burnout: Pearson product-moment correlation coefficients, $N=158$.

\begin{tabular}{|c|c|c|c|c|}
\hline Variable & Burnout & Exhaustion & Cynicism & Professional efficacy \\
\hline \multirow[t]{2}{*}{$\overline{\mathrm{EE}}$} & -0.55948 & -0.44627 & -0.41778 & -0.40383 \\
\hline & $<0.0001 * *$ & $<0.0001 * *$ & $<0.0001 * *$ & $<0.0001 * *$ \\
\hline \multirow[t]{2}{*}{ Customer service } & -0.45137 & -0.33203 & -0.34732 & -0.34994 \\
\hline & $<0.0001 * *$ & $<0.0001 * *$ & $<0.0001 * *$ & $<0.0001 * *$ \\
\hline \multirow[t]{2}{*}{ Immediate manager } & -0.37042 & -0.30979 & -0.28835 & -0.23662 \\
\hline & $<0.0001 * *$ & $<0.0001 * *$ & $0.0002 * *$ & $0.0028 * *$ \\
\hline \multirow[t]{2}{*}{ Organisational commitment } & -0.55148 & -0.42971 & -0.43813 & -0.38240 \\
\hline & $<0.0001 * *$ & $<0.0001 * *$ & $<0.0001 * *$ & $<0.0001 * *$ \\
\hline \multirow[t]{2}{*}{ Organisational satisfaction } & -0.67298 & -0.52758 & -0.57158 & -0.42272 \\
\hline & $<0.0001 * *$ & $<0.0001 * *$ & $<0.0001 * *$ & $<0.0001 * *$ \\
\hline \multirow[t]{2}{*}{ Strategy implementation } & -0.43306 & -0.37189 & -0.27872 & -0.32752 \\
\hline & $<0.0001 * *$ & $<0.0001 * *$ & $0.0004 * *$ & $<0.0001 * *$ \\
\hline
\end{tabular}

EE, employee engagement.

${ }^{* *} p \leq 0.05$.

TABLE 2: Correlations between subscales of burnout and self-perceived employability: Pearson product-moment correlation coefficients, $N=158$, Prob > $|r|$ under HO: Rho $=0$.

\begin{tabular}{|c|c|c|c|c|}
\hline Variables & Burnout & Exhaustion & Cynicism & Professional efficacy \\
\hline \multirow[t]{3}{*}{ Employability } & -0.07937 & -0.00100 & 0.00041 & -0.20020 \\
\hline & 0.3215 & 0.9901 & 0.9960 & $0.0117 * *$ \\
\hline & 158 & 158 & 158 & 158 \\
\hline \multirow[t]{3}{*}{ Career self-management } & -0.11466 & -0.03141 & -0.06791 & -0.17747 \\
\hline & 0.1514 & 0.6953 & 0.3965 & $0.0257 * *$ \\
\hline & 158 & 158 & 158 & 158 \\
\hline \multirow[t]{3}{*}{ Cultural competence } & -0.08960 & -0.04467 & -0.02063 & -0.14910 \\
\hline & 0.2645 & 0.5785 & 0.7976 & 0.0624 \\
\hline & 157 & 157 & 157 & 157 \\
\hline \multirow[t]{3}{*}{ Self-efficacy } & 0.07657 & 0.13700 & 0.11660 & -0.10391 \\
\hline & 0.3405 & 0.0871 & 0.1459 & 0.1953 \\
\hline & 157 & 157 & 157 & 157 \\
\hline \multirow[t]{2}{*}{ Career resilience } & -0.05418 & -0.01240 & 0.03024 & -0.15429 \\
\hline & 0.4990 & 0.8771 & 0.7060 & $0.0529 * *$ \\
\hline \multirow[t]{3}{*}{ Sociability } & -0.06633 & 0.04498 & 0.00404 & -0.22898 \\
\hline & 0.4076 & 0.5746 & 0.9598 & $0.0038 * *$ \\
\hline & 158 & 158 & 158 & 158 \\
\hline \multirow[t]{3}{*}{ Entrepreneurial orientation } & 0.00865 & 0.05410 & 0.07286 & -0.12487 \\
\hline & 0.9144 & 0.5010 & 0.3645 & 0.1192 \\
\hline & 157 & 157 & 157 & 157 \\
\hline \multirow[t]{3}{*}{ Proactivity } & -0.11974 & -0.03882 & -0.05054 & -0.19980 \\
\hline & 0.1340 & 0.6282 & 0.5283 & $0.0118 * *$ \\
\hline & 158 & 158 & 158 & 158 \\
\hline \multirow[t]{3}{*}{ Emotional literacy } & -0.10314 & -0.06757 & -0.00313 & -0.17360 \\
\hline & 0.1986 & 0.4004 & 0.9690 & $0.0297 * *$ \\
\hline & 157 & 157 & 157 & 157 \\
\hline
\end{tabular}

$* * p \leq 0.05$.

(Coetzee et al., 2016), and employees who possess SPE as a personal resource experience fewer psychosocial stressors (De Cuyper, Raeder, Van der Heijden, \& Wittekind, 2012; Lu et al., 2016).

None of the dimensions of the employability scale correlated significantly with the EX and CY variables. The relationship between the overall $\mathrm{BO}$ and the overall employability was negative, but not significant. Table 3 summarises the correlations between EE and SPE. The results show a positive, but not significant, correlation between EE and SPE ( $r=0.11040 ; p \leq 0.1673$; positive small effect size). Two dimensions of EE, namely customer service and strategy and implementation, correlated significantly with some of the dimensions of employability. The results of the study in terms of the levels of $\mathrm{BO}$ and the levels of EE differ from the findings of most studies conducted within the South African public sector. Within the South African public sector context, numerous studies have reflected on the high levels of BO (Maslach \& Leiter, 2016; Schaufeli et al., 2009). Studies have also reflected on persistent, negative, work-related issues where government departments and municipalities have to deal with numerous concerns regarding the quality of service delivery amidst limited resources (Lehohla, 2016; Rothmann, Jackson, \& Kruger, 2003). 
TABLE 3: Correlations between subscales of employee engagement and self-perceived employability: Pearson product-moment correlation coefficients, $N=158$.

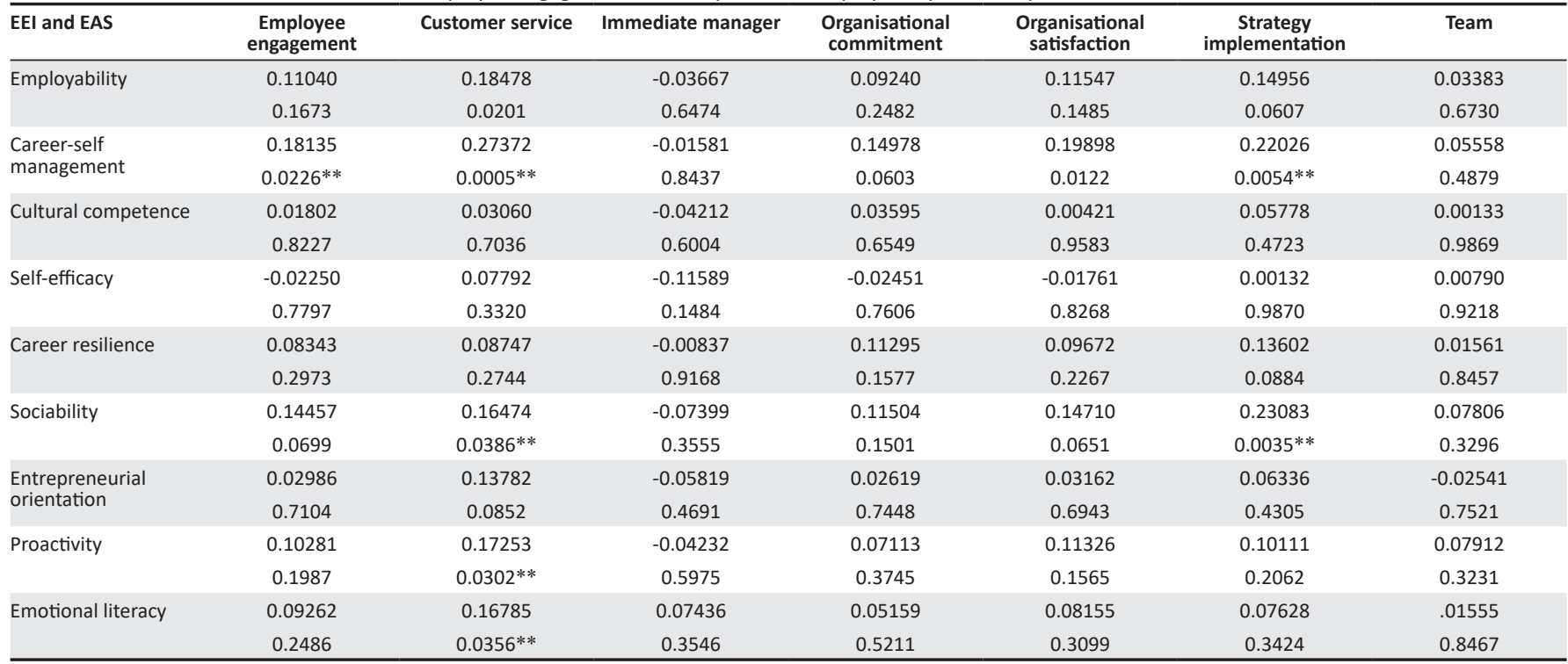

EEI, employee engagement instrument; EAS, employability attributes scale.

${ }^{* *} p \leq 0.05$.

Prob $>|r|$ under $\mathrm{HO}: \mathrm{Rho}=0$

Customer service positively correlated significantly with the overall employability $(p=0.021)$ and the employability dimensions, namely career self-management $(p=0.0005)$, sociability $(p=0.034)$ and proactivity $(p=0.030)$. The correlations vary from $r=0.164$ (small effect size) to $r=0.27$ (medium effect size) at $p<0.05$. This means that as the level of customer service positively increases, the variables overall employability, sociability and proactivity also increase.

Strategy and implementation correlated significantly and positively with career self-management $(r=0.22 ; p=0.0054$; small effect size) and sociability $(r=0.23 ; p=0.0035$; small size effect). The results show that the more the participants' level of strategy and implementation positively increases, the more the levels of career self-management and sociability increase.

Table 4 provides the overall summary of the relationship between $\mathrm{BO}, \mathrm{EE}$ and SPE. Employee engagement relates negatively with $\mathrm{BO}$ and the correlation is statistically significant $(r=-0.56 ; p<0.0001$; negative large effect size). Self-perceived employability relates negatively to $\mathrm{BO}$ but the correlation is not significant $(\mathrm{r}=-0.09647 ; p<0.2279$; small effect size). The strength of the relationship between $\mathrm{BO}$ and SPE is weak and a conclusion in terms of the relationship cannot be accepted. There is a significant body of research on BO in human services occupations such as police, nurses, social workers, teachers and doctors within the South African public sector context (Schaufeli et al., 2009; Sôderfeldt, Sôderfeldt, \& Warg, 1995). Most of these studies have reported high levels of $\mathrm{BO}$ experienced by employees and low levels of EE.

The current study was conducted in a non-human services public sector organisation where the mandate is performed behind a desk (office work) and does not involve serving people directly. It includes performing work at a professional, managerial or administrative level. The differences in terms of the nature of work and environment contributed to the findings.

Based on the correlational analysis, a negative and significant correlation between $\mathrm{BO}$ and EE was found. Also, a negative but non-significant relationship between $\mathrm{BO}$ and SPE was found. Furthermore, a positive but nonsignificant relationship between EE and SPE was found. Positive and significant correlations were found between EE dimensions, namely customer service and strategy and implementation, as well as between employability dimensions, namely career self-management sociability and proactivity.

\section{Multiple regression analysis}

A multiple regression analysis was used to determine the regression between $\mathrm{BO}, \mathrm{EE}$ and $\mathrm{SPE}$, as well as the relationship between the demographic variables, BO, EE and SPE.

\section{Regression analysis with burnout as the dependent variable and employee engagement, self-perceived employability and demographics as the independent variables}

Table 5 summarises the regression model between the biographical variables (age, gender, racial groups, marital status and tenure) and EE and its subscales (customer service, immediatemanager, organisational commitment, organisational satisfaction, strategy and implementation, and team), SPE and its subscales (career self-management, cultural competence, self-efficacy, career resilience, sociability, entrepreneurial orientation, proactivity, emotional literacy) as the independent variables and $\mathrm{BO}$ as the dependent variable. 
The regression of the EE subscales, SPE subscales and demographic variables on BO produced a statistically significant model $(F=7.66 ; p<0.0001)$, accounting for $56 \%$ $\left(R^{2}=0.56\right.$; large practical size effect) of the variance in the BO variable. The regression of the demographic variables (age, qualification, marital status and gender) on $\mathrm{BO}$ was negative but not statistically significant. For race and tenure, the regression was positive, but not statistically significant. The regression of the $\mathrm{EE}$ subscales on $\mathrm{BO}$ was not statistically significant except for organisational satisfaction $(p=-0.78 ; r<0.0001)$ and team $(p=0.202 ; r=0.0276)$. For the regression of SPE on $\mathrm{BO}$, only one of the dimensions of the $\mathrm{EE}$, namely proactivity ( $p=-0.49=-2.29 ; r=0.0133$ ) was statistically significant.

TABLE 4: Correlations between subscales of burnout, employee engagement and self-perceived employability: Pearson product-moment correlation coefficients, $N=158$, Prob $>|r|$ under $\mathrm{HO}$ : Rho $=0$.

\begin{tabular}{lcccc}
\hline Variables & Burnout & Exhaustion & Cynicism & $\begin{array}{c}\text { Professional } \\
\text { efficacy }\end{array}$ \\
\hline $\begin{array}{l}\text { Employee } \\
\text { engagement }\end{array}$ & -0.55948 & -0.44627 & -0.41778 & -0.40383 \\
$p$ & $<0.0001^{* *}$ & $<0.0001^{* *}$ & $<0.0001^{* *}$ & $<0.0001^{* *}$ \\
Employability & -0.07937 & -0.00100 & 0.00041 & -0.20020 \\
$p$ & 0.3215 & 0.9901 & 0.9960 & $0.0117^{* *}$ \\
\hline
\end{tabular}

$* * p \leq 0.05$.
Regression analysis with burnout as the dependent variable and employee engagement and self-perceived employability as the independent variables

As shown in Table 6, the regression of the EE and SPE variables on the $\mathrm{BO}$ variable produced a statistically significant model $(F=35.36 ; p<0.0001)$, accounting for $R^{2}=0.31$ (large practical effect size) of the variance in the $\mathrm{BO}$ variable. The regression analysis in terms of the $\mathrm{EE}$ with BOproduced a negative and statistically significant (standardised estimate $=-0.81 ; \operatorname{Pr}<0.00)$ regression. In terms of the regression between SPE variables and $\mathrm{BO}$, the regression was negative but no statistically significant regression was produced (standardised estimate $=-0.02$; $\operatorname{Pr}<0.79$ ).

Burnout produced a negative and statistically significant regression with EE. Burnout produced a negative but not statistically significant regression with SPE. The regression of the demographic variables (age, qualification, marital status and gender) on $\mathrm{BO}$ was negative but not statistically significant. The EE subscales on $\mathrm{BO}$ for organisational satisfaction and team produced a statistically significant regression. The SPE instrument on BO produced a statistically significant regression on proactivity.

TABLE 5: Multiple regression statistics summary: Burnout as dependent variable and employee engagement, self-perceived employability and demographics as independent variables.

\begin{tabular}{|c|c|c|c|c|c|c|c|c|}
\hline Variable & $\begin{array}{c}\text { Parameter } \\
\text { estimate }\end{array}$ & Standard error & Standardised & $t$ & $p$ & $F$ & Adjusted $R$ square & $R$ \\
\hline Intercept & 3.85258 & 0.65020 & 0 & 5.93 & $<0.0001$ & 7.66 & 0.4876 & 0.5608 \\
\hline Gender & -0.14661 & 0.12552 & -0.07661 & -1.17 & 0.2449 & - & - & - \\
\hline Race & 0.49607 & 0.29541 & 0.22649 & 1.68 & 0.0955 & - & - & - \\
\hline Qualification & -0.14386 & 0.13311 & -0.07480 & -1.08 & 0.2818 & - & - & - \\
\hline Marital status & -0.06748 & 0.11898 & -0.03554 & -0.57 & 0.5716 & - & - & - \\
\hline Job level & 0.20532 & 0.15497 & 0.09202 & 1.32 & 0.1875 & - & - & - \\
\hline Age & -0.17655 & 0.16605 & -0.09068 & -1.06 & 0.2896 & - & - & - \\
\hline Tenure & 0.01409 & 0.14401 & 0.00726 & 0.10 & 0.9222 & - & - & - \\
\hline Customer service & -0.03366 & 0.10782 & -0.02805 & -0.31 & 0.7554 & - & - & - \\
\hline Immediate manager & -0.02128 & 0.07629 & -0.02191 & -0.28 & 0.7807 & - & - & - \\
\hline Organisational commitment & -0.15915 & 0.12495 & -0.12944 & -1.27 & 0.2050 & - & - & - \\
\hline Organisational satisfaction & -0.78603 & 0.12212 & -0.69158 & -6.44 & $<0.0001 * *$ & - & - & - \\
\hline Strategy & 0.12931 & 0.10830 & 0.12032 & 1.19 & 0.2346 & - & - & - \\
\hline Career-self management & 0.01844 & 0.14055 & 0.01549 & 0.13 & 0.8958 & - & - & - \\
\hline Cultural competence & -0.14027 & 0.08712 & -0.13559 & -1.61 & 0.1098 & - & - & - \\
\hline Self-efficacy & 0.22436 & 0.12966 & 0.16300 & 1.73 & 0.0859 & - & - & - \\
\hline Career-resilience & 0.18491 & 0.17125 & 0.14431 & 1.08 & 0.2822 & - & - & - \\
\hline Sociability & 0.22235 & 0.13851 & 0.20135 & 1.61 & 0.1108 & - & - & - \\
\hline Entrepreneurial orientation & 0.20380 & 0.15437 & 0.15133 & 1.32 & 0.1891 & - & - & - \\
\hline Proactivity & -0.49359 & 0.19672 & -0.38226 & -2.51 & $0.0133^{* *}$ & - & - & - \\
\hline Emotional literacy & -0.14126 & 0.10560 & -0.12270 & -1.34 & 0.1833 & - & - & - \\
\hline
\end{tabular}

${ }^{* *} p \leq 0.05 ;+R^{2} \leq 0.12$ (small practical size effect); $++R^{2} \geq 0.13 \leq 0.25$ (medium practical size effect; $+++R^{2} \geq 0.26$ (large practical size effect).

TABLE 6: Multiple regression statistics summary: Burnout as a dependent variable and employee engagement and self-perceived employability as an independent variable.

\begin{tabular}{|c|c|c|c|c|c|c|c|c|}
\hline \multirow[t]{2}{*}{ Variable } & \multicolumn{2}{|c|}{ Unstandardised } & \multirow{2}{*}{$\begin{array}{l}\text { Standardised } \\
\text { estimate }\end{array}$} & \multirow[t]{2}{*}{$t$} & \multirow[t]{2}{*}{$p$} & \multirow[t]{2}{*}{$F$} & \multirow{2}{*}{ Adjusted $R$ square } & \multirow[t]{2}{*}{$R$} \\
\hline & Parameter estimate & Standard error & & & & & & \\
\hline Intercept & 4.82429 & 0.53463 & 0 & 9.02 & $<0.0001^{* *}$ & 35.36 & 0.3045 & 0.3133 \\
\hline Employability & -0.02571 & 0.09663 & -0.01782 & -0.27 & 0.7905 & - & - & - \\
\hline Employee engagement & -0.81768 & 0.09822 & -0.55752 & -8.33 & $<0.0001^{* *}$ & - & - & - \\
\hline
\end{tabular}

${ }^{* *} p \leq 0.05 ;+R^{2} \leq 0.12$ (small practical size effect); $++R^{2} \geq 0.13 \leq 0.25$ (medium practical size effect; $+++R^{2} \geq 0.26$ (large practical size effect) 


\section{Test for significant mean differences}

The test for significant mean differences was conducted for all three constructs regarding the demographics on age, marital status, race, gender, tenure and qualification.

\section{Age}

No statistically significant mean differences were found between the participants who were below or equal to 35 years and the participants older than 35 years in terms of $\mathrm{BO}, \mathrm{EE}$ and SPE (Table 7). Some researchers found that age differs significantly across these groups (Bezuidenhout, 2008; Schaufeli \& Bakker, 2003), whilst others have found no statistically significant mean differences between age and the different groups (BO, EE and SPE) (Karli, 2016; Luk et al., 2010; Shukla, Adhikari, \& Singh, 2015).

\section{Marital status}

Table 8 shows that the mean scores and SDs on all the dimensions for married and unmarried participants were similar and no significant differences were found. A study by Asgari (2012) found that there was no significant difference between the groups regarding marital status.

\section{Race}

Results on race indicate no significant mean differences between age and EE. However, on two of the subscales of EE, namely organisational commitment (black group, $M=3.81$; and the white group, $M=3.52$ ) and strategy implementation (black group, $M=2.99$, and the white group, $M=2.56$ ) significant mean differences were found between the racial groups. The results demonstrate that the black group obtained the highest mean score compared to the white group in terms

\begin{tabular}{lcccc}
\multicolumn{3}{l}{ TABLE 7: Significant mean differences: Age. } & \multicolumn{1}{l}{} & \\
\hline Age categories & $N$ & Mean & Std. deviation & Sig \\
\hline Burnout overall score & & & & \\
35 years and younger & 42 & 1.8878 & 0.94358 & 0.881 \\
Older than 35 years & 116 & 1.9141 & 0.98231 & \\
$\begin{array}{l}\text { Employee engagement } \\
\text { overall score }\end{array}$ & & & & \\
35 years and younger & 42 & 3.5257 & 0.78052 & 0.593 \\
Older than 35 years & 116 & 3.4634 & 0.59006 & \\
Employability overall score & & & & \\
35 years and younger & 42 & 4.6185 & 0.68241 & 0.859 \\
Older than 35 years & 116 & 4.5976 & 0.64248 & \\
\hline
\end{tabular}
$p \leq 0.05$.

TABLE 8: Significant mean differences: Marital status.

\begin{tabular}{lccccc}
\hline Marital status & $N$ & Mean & $\begin{array}{c}\text { Std. } \\
\text { deviation }\end{array}$ & $\begin{array}{c}\text { Std. error } \\
\text { mean }\end{array}$ & Sig \\
\hline Burnout & 87 & 1.9130 & 0.94472 & 0.10128 & 0.933 \\
Married & 71 & 1.8998 & 1.00520 & 0.11930 & - \\
Unmarried & & & & & \\
Employee engagement & 87 & 3.4276 & 0.66003 & 0.07076 & 0.259 \\
Married & 71 & 3.5442 & 0.62267 & 0.07390 & - \\
Unmarried & & & & & \\
Employability & 87 & 4.6323 & 0.67279 & 0.07213 & 0.535 \\
Married & 71 & 4.5674 & 0.62661 & 0.07436 & - \\
Unmarried & & & & &
\end{tabular}

of organisational commitment, showing that the black group experiences the dimension of organisational commitment significantly more positively than the white group. The black group also obtained a higher mean score compared to the white group in terms of strategy and implementation, and experienced this dimension of strategy and implementation significantly more positively than the white group.

In terms of SPE, statistically significant mean differences were found between the racial groups and SPE and its subscales. Overall, the mean scores of the black group ( $M=4.68)$ were higher than the mean scores of the white group $(M=4.36)$. The significant mean scores for the subscales were as follows: self-efficacy (black group, $M=4.84$; white group, $M=4.58$ ), career resilience (black group, $M=4.64$; white group, $M=4.32$ ), sociability (black group, $M=4.4260$; white group, $M=3.78$ ), entrepreneurial orientation (black group, $M=4.7615$; white group, $M=4.3828$ ) and career self-management (black group, $M=4.86$; white group, $M=4.21)$. The results show that black participants experienced SPE significantly higher. These findings are consistent with findings by Qenani et al. (2014), which confirmed the influence that race has in terms of SPE. Oosthuizen, Coetzee and Mntonintshi (2014) found that respondents from different race groups differed significantly in terms of entrepreneurial creativity.

\section{Gender}

The results show no statistically significant mean differences between gender for BO, EE and SPE. However, significant mean differences in gender were found in terms of SPE dimensions, namely entrepreneurial orientation (males, $M=4.8$; females, $M=4.58$ ), and proactivity (males, $M=4.88$; females, $M=4.62$ ). Male participants experienced the dimensions of entrepreneurial orientation and proactivity significantly more positively than female participants. These findings were consistent with the findings of other researchers who found that females tend to consider themselves less employable compared to men (Qenani et al., 2014; Vargas et al., 2018). The reasons for this trend could be many, including the issue of gender inequality in South Africa. Government has recognised issues of gender inequality and have initiated strategies and programmes towards achieving gender equality of employees in the workplace (DPSA, 2006).

\section{Tenure}

Tenure was clustered in participants with less or more than 10 years' work experience. Significant mean differences were found between EE (less than 10 year, $M=3.6498 ; 10$ years and above, $M=3.37$ ); customer service (less than 10 years, $M=3.58 ; 10$ years and above, $M=3.23$ ); organisational satisfaction (less than 10 years, $M=3.6630 ; 10$ years and above, $M=3.35$ ); and strategy and implementation (less than 10 years, $M=3.12$; 10 years and above, $M=2.73$ ). In terms of all the listed variables, the participants with less than 10 years of work experience were more positively engaged compared to the others. According to De Lange, 
De Witte and Notelaers (2008), employees working in a single organisation for a long time tend to show lower levels of EE, whilst employees with fewer years of experience are more engaged.

\section{Qualification}

Finally, the results show that significant mean differences were found between qualification categories and the dimensions of EE, namely organisational commitment (participants with a matric qualification, $M=3.9444$; participants with an undergraduate qualification, $M=3.8315$; participants with a postgraduate qualification, $M=3.5392$ ) and strategy and implementation (participants with a matric qualification, $M=3.25$; participants with an undergraduate qualification, $M=2.94$; participants with a postgraduate qualification, $M=2.67$ ), in terms of organisational commitment. Thus, the results show a trend that the EE level reduces as the respondents' qualification levels increase (Rothmann \& Rothmann, 2010).

\section{Discussion}

The results indicate that employees experience low levels of BO and hardly suffer from physical and emotional work stressors. The moderate to high levels of EE shows that employees are proactive, productive, committed and attached to their work (Martins \& Ledimo, 2016). The results regarding $\mathrm{BO}$ and $\mathrm{EE}$ differ from most results obtained by previous South African studies. They mainly focused on human services occupations (police, health care, social welfare) (Palazzo, Carlotto, \& Aerts, 2008; Schaufeli et al., 2008; Tsigilis, Zachopoulou, \& Grammatikopoulos, 2006), whilst this study was conducted in a diplomatic, office-work environment that is characterised as non-human service occupations (Brand-Labuschagne et al., 2012). The results confirm the negative relationship between $\mathrm{BO}$ and $\mathrm{EE}$, which is consistent with previous studies (Rothmann \& Rothmann, 2010; Schaufeli et al., 2009) and show that engaged employees are more productive and provide better customer service (Nienaber \& Martins, 2015). They can better cope with work challenges, are more resilient and manage stressful situations better (Maslach, 2011; Moodley, 2010).

Considering the low scores in $\mathrm{BO}$, the results confirm previous studies, showing that employees who possess more attributes of SPE experience fewer symptoms of BO (Lu et al., 2016). Additionally, samples from the various demographic groups (race, qualifications, tenure and gender) differed significantly in their levels of EE and SPE. No significant mean differences were found between $\mathrm{BO}$ and any of the biographical variables. A negative relationship exists between $\mathrm{BO}$ as the dependent variable and $\mathrm{EE}$ and SPE as the independent variables. Burnout was found to have a statistically significant, negative relationship with EE (as in previous studies), but no statistically significant relationship was found between BO and SPE. Engaged employees tend to be in control of their work situation (Gupta \& Sharma, 2016;
Moodley, 2010), are happier, more productive, are competitive and provide better customer service than others (Nienaber \& Martins, 2015). Therefore, they experience lower BOlevels, improved coping, resilience and stress management (Maslach, 2011; Moodley, 2010). The results indicated a statistically insignificant, negative relationship between $\mathrm{BO}$ and SPE, opposing previous study results that revealed a negative relationship between SPE and BO (Lu et al., 2016). Employees with high SPE are proactive, focus on career progression (Coetzee et al., 2015) and experience fewer symptoms of BO (Lu et al., 2016).

The results showed a positive but not significant correlation between EE and SPE. Customer service (EE dimension) positively correlated significantly with the SPE as well as with career self-management, sociability and proactivity. By this, the participants demonstrated taking care of customers' needs and providing professional quality service, whilst perceiving themselves as capable of managing their careers, being sociable and innovative. Strategy and implementation also correlated significantly and positively with career self-management and sociability, showing encouragement and positive morale about the institution's objectives.

The results provided evidence that EE and SPE negatively relate to $\mathrm{BO}$. However, the correlation was only significant in terms of $\mathrm{BO}$ and $\mathrm{EE}$, but not significant in terms of $\mathrm{BO}$ and $\mathrm{SPE}$, and it displayed that the sample perceived themselves as employable. They scored lower on BO and experienced lower levels of BO, supporting previous research and showing that employees who possess personal resources (e.g. SPE) experience fewer symptoms of BO (Lu et al., 2016). This study, as well as previous studies (Asgari, 2012; Anand et al., 2016), have not found significant differences between marital status and the different groups regarding all three constructs. Researchers found that age differs significantly across these groups (Bezuidenhout, 2008; Schaufeli \& Bakker, 2003), whilst others have found no statistically significant mean differences between age and the different groups (BO, EE and SEP) (Luk et al., 2010; Shukla et al., 2015; Karli, 2016), as in this study. The results show that the male participants experienced the dimensions of entrepreneurial orientation and proactivity significantly more positively than the female participants. These results are consistent with research stating that females tend to consider themselves less employable compared to men (Qenani et al., 2014; Vargas et al., 2018). This could be rooted in gender inequality issues in South Africa, as highlighted by the South African Government (DPSA, 2006).

The black group obtained higher mean scores in EE than the white group (in organisational commitment and strategy and implementation), meaning that the black group experienced these dimensions significantly more positively. These differences have been observed before (Oosthuizen et al., 2014). However Segal (2009) highlights contradictions, showing that black employees tend to show less EE 
compared to their white counterparts. The significant mean differences between SPE and race were found on selfefficacy, career resilience, sociability, entrepreneurial orientation and career self-management. The results show that the black participants experienced SPE significantly more positive than the white participants. The results support Qenani et al. (2014), presenting the influence of race, whilst Oosthuizen et al. (2014) show significant differences in terms of race and entrepreneurial creativity. The results further support Barkhuizen and Rothmann (2006), showing that EE levels decrease as the qualification level increases. Significant mean differences were found between EE and its dimensions: customer service, organisational satisfaction, and strategy and implementation, showing participants with less than 10 years' work experience being more positively engaged at work, thereby supporting De Lange et al. (2008).

\section{Conclusion and recommendations}

Approaches to reduce BO have hardly considered EE and SPE amongst employees before and should consider EE and SPE as effective tools to enhance employees' wellness, morale and productivity. Improving EE and enhancing employees' employability increases employee well-being. The increased well-being will positively impact on limiting $\mathrm{BO}$ and help alleviate employee BO. The current study showed that EE and SPE were negatively related to $\mathrm{BO}$. Although the relations were only statistically significant between $\mathrm{BO}$ and EE, both the constructs appeared as effective tools for reducing $\mathrm{BO}$ and enhancing employees' well-being and work productivity. Strategies to alleviate or prevent BO should consider the differences observed between age, race, tenure, qualification, gender and marital status in terms of their EE and SPE attributes.

The majority of the black participants, males, those with fewer years of work experience, and the least qualified employees were more engaged and possessed relatively more of the employability attributes compared to the other groups. These results indicate that wellness programmes could aim to particularly foster members of a specific subgroup in the organisation to promote well-being. Such programmes could enhance the understanding of these groups; about how their levels of EE and perceived employability influence their performance in terms of service delivery and how their health and wellness relate to their capability of being fully engaged and employable.

In terms of recommendations, larger and in-depth studies are needed in white-collar institutions within South Africa's public sector to increase the understanding of the different concepts and their interrelationships. Future studies should focus on exploring the relationship between $\mathrm{BO}$ and $\mathrm{EE}$ outside human services institutions to investigate the various relationships in more depth. It is also recommended to replicate this study in different institutions in South Africa and different countries to validate the results and to generalise results based on larger populations. Finally, it emphasises that future research should investigate SPE as a psychosocial resource mechanism on the issues of $\mathrm{BO}$ and $\mathrm{EE}$. On a practical note, I/O psychologists and HR practitioners should consider how EE and SPE affect employees' BO in their employee wellbeing programmes, training and courses, as well as in terms of creating employee awareness and healthy mindsets.

\section{Limitations}

The correlational design was limited to examining only the strength and direction of the relations between the variables that were studied. As a result of the application of the convenience sampling approach, unequal distribution of the respondents in terms of gender groups was obtained, causing the need for the study to be replicated in broader samples and different public sector institutions but of a similar nature, for a more comprehensive conclusion to be drawn about the relationship. In addition, as the convenience sampling method was used, results are also not generalisable whereas a random sampling method may have improved the generalisability of the findings.

\section{Acknowledgements}

The public service organisation and the respondents who participated in the study are acknowledged.

\section{Competing interests}

The authors have declared that no competing interests exist.

\section{Authors' contribution}

N.Z. was the project leader, and R.O. of the University of South Africa and C.M. of the University of Johannesburg wrote the manuscript.

\section{Funding information}

This research received no specific grant from any funding agency in the public, commercial or not-for-profit sectors.

\section{Data availability}

Data sharing is applicable to this article as new data were created and analysed in this study.

\section{Disclaimer}

The views and opinions expressed in this article are those of the authors and do not necessarily reflect the official policy or position of any affiliated agency of the authors.

\section{References}

Anand, V.V., Banu, C.V., Rengarajan, V., Thirumoorthy, G., Rajkumar, V., \& Madhumitha, R. (2016). Employee engagement-A study with special reference to postal employees in rural areas of Thanjavur. Indian Journal of Science and Technology, 9(27), 1-8. https://doi.org/10.17485/ijst/2016/v9i11/8845

Asgari, A. (2012). The effects of gender and marital status on burnout of English teachers in Iran. Pertanika Journal of Social Sciences \& Humanities, 20(3), 635-644. 
Barkhuizen, N., \& Rothmann, S. (2006). Work engagement of academic staff in South African higher education institutions. Management Dynamics: Journal of the Southern African Institute for Management Scientists, 15(1), 38-46.

Bell, D. S., \& Bell, D. E. (2010). Definition of recovery in chronic fatigue syndrome. Journal of liMe, 4, 23-27.

Bezuidenhout, A. (2008). Burnout, work engagement and sense of coherence in female academics at two tertiary institutions in South Africa. Unpublished Doctoral dissertation. Pretoria: University of South Africa.

Bosman, J., Rothmann, S., \& Buitendach, J.H. (2005). Job insecurity, burnout and work engagement the impact of positive and negative affectivity. South African Journa of Industrial Psychology, 31(4), 48-56. https://doi.org/10.4102/sajip.v31i4.199

Brand-Labuschagne, L., Mostert, K., Rothmann, S., \& Rothmann, J.C. (2012). Burnout and work engagement of South African blue-collar workers: The development of a new scale. Southern African Business Review, 16(1), 58-93.

Coetzee, M., Oosthuizen, R.M., \& Stoltz, E. (2015). Psychosocial employability attributes as predictors of staff satisfaction with retention factors. South African Journal of Psychology, 46(2), 232-243. https://doi.org/10.1177/ African Journal of

Coetzee, M., Roythorne-Jacobs, H., \& Mensele, C. (2016). Career counselling and guidance in the workplace: A manual for career practitioners. Cape Town: Juta and guidance in the

Cohen, J. (1992). Quantitative methods in psychology: A power primer. Psychological Bulletin, 112(1), 153-159. https://doi.org/10.1037/0033-2909.112.1.155

De Cuyper, N., Raeder, S., Van der Heijden, B.I., \& Wittekind, A. (2012). The association between workers employability and burnout in a reorganization context: Longitudinal evidence building upon the conservation of resources theory. Journal of Occupational Health Psychology, 17(2), 162-174. https://doi.org/ 10.1037/a0027348

De Lange, A.H., De Witte, H., \& Notelaers, G. (2008). Should I stay or should I go? Examining longitudinal relations among job resources and work engagement for stayers versus movers. Work \& Stress, 22(3), 201-223. https://doi.org/10.1080/ 02678370802390132

Department of Public Service and Administration (DPSA). (2015). Annual repor 2014/15. Retrieved from http://www.dpsa.gov.za

Department of Public Service and Administration (DPSA). (2016). Annual performance plan 2015/16. Retrieved from http://www.dpsa.gov.za

De Villiers, C.J., \& Hsiao, P.C.K. (2017). A review of accounting research in internationalising journals in the South African region. South African Journal of Economic and Management Sciences, 20(1), 1-18. https://doi.org/10.4102/sajems.v20i1.1729

Fragoso, Z.L., Holcombe, K.J., McCluney, C.L., Fisher, G.G., McGonagle, A.K., \& Friebe, S.J. (2016). Burnout and engagement: Relative importance of predictors and S.J. (2016). Burnout and engagement: Relative importance of predictors and
outcomes in two healthcare worker samples. Workplace Health \& Safety, 64(10), outcomes in two healthcare worker samples. Workplace

Guan, S., Xiaerfuding, X., Ning, L., Lian, Y., Jiang, Y., Liu, J., \& Ng, T.B. (2017). Effect of job strain on job burnout, mental fatigue and chronic diseases among civil servants in the Xinjiang Uygur autonomous region of China. International Journal servants in the Xinjiang Uygur autonomous region of China. International Journal
of Environmental Research and Public Health, 14(8), 872. https://doi.org/10.3390/ ijerph14080872

Gupta, N., \& Sharma, V. (2016). Exploring employee engagement - A way to better business performance. Global Business Review, 17(3), 45S-63S. https://doi. org/10.1177/0972150916631082

Hirayama, M., \& Fernando, S. (2016). Burnout in surgeons and organisational interventions. Journal of the Royal Society of Medicine, 109(11), 400-403. https:// doi.org/10.1177/0141076816666810

Howell, D.C. (2004). Fundamental statistics for the behavioral sciences (5th edn.) Belmont, CA: Thomson-Brooks/Cole.

Karli, U. (2016). Adaptation and validation of self-perceived employability scale: An analysis of sports department students and graduates. Educational Research and Reviews, 11(8), 848-859.

Kosuta, K. (2010). Shifting sand: Examining employee engagement in the public sector Athabasca University. February.

Lehohla, P. (2016). The state of basic service delivery in South Africa: In-depth analysis of the community survey 2016 data. Report no. 03-01-22, 2016. Pretoria: Statistics South Africa.

Levin, D.M., Szabat, K.A., \& Stephen, D.F. (2016). Business statistics: A first course (7th edn.). Harlow, Essex: Pearson Education Limited.

Lindén, M., Salo, I., \& Jansson, A. (2016). Organizational stressors and burnout in public librarians. Journal of Librarianship and Information Science, 50(2), 199-204. https://doi.org/10.1177/0961000616666130

Lu, C.Q., Sun, J.W., \& Du, D.Y. (2016). The relationships between employability emotional exhaustion, and turnover intention: The moderation of perceived career opportunity. Journal of Career Development, 43(1), 37-51. https://doi. org/10.1177/0894845315576372

Luk, A.L., Chan, B.P.S., Cheong, S.W., \& Ko, S.K.K. (2010). An exploration of the burnout situation on teachers in two schools in Macau. Social Indicator Research, 95(3), 489-502. https://doi.org/10.1007/s11205-009-9533-7

Martins, N. (2015). Testing for measurement invariance for employee engagement across sectors in South Africa. Journal of Contemporary Management, 12(1), 757-774

Martins, N., \& Ledimo, O. (2016). The measurement of employee engagement in government institutions. Journal Risk Governance and Control, 6(3), 18-25. https://doi.org/10.22495/rcgv6i3art3
Maslach, C. (2011). Burnout and engagement in the workplace: New perspectives. European Health Psychologist, 13(3), 44-47. https://doi.org/10.1037/ e544732013-003

Maslach, C., \& Leiter, M.P. (2016). Understanding the burnout experience: Recent research and its implications for psychiatry. World Psychiatry, 15(2), 103-111. https://doi.org/10.1002/wps.20311

Maslach, C., Schaufeli, W.B., \& Leiter, M.P. (2001). Job burnout. Annual Review of Psychology, 52(1), 397-422. https://doi.org/10.1146/annurev.psych.52.1.397

Mattke, S., Liu, H.H., Caloyers, J.P., Huang, C.Y., Van Busum, K.R., Khodyakov, D., \& Shier, V. (2013). Workplace wellness programs study. Rand Health Quarterly, 3(2), 7. https://doi.org/10.7249/RR254

Moodley, S.N. (2010). Personality and work engagement in a financial institution. Doctoral dissertation. Cape Town: University of South Africa.

Nienaber, H., \& Martins, N. (2015). Validating a scale measuring engagement in a South African context. Journal of Contemporary Management, 12(1), 401-425.

Palazzo, L.D.S., Carlotto, M.S., \& Aerts, D.R.G.de C. (2012). Burnout syndrome: Population-based study on public servants. Revista de Saude Publica, 46(6), 1066-1073. https://doi.org/10.1590/S0034-89102013005000004

Potgieter, I., \& Coetzee, M. (2013). Employability attributes and personality preferences of postgraduate business management students. SA Journal of Industrial Psychology, 39(1), 1-10. https://doi.org/10.4102/sajip.v39i1.1064

Qenani, E., MacDougall, N., \& Sexton, C. (2014). An empirical study of self-perceived employability: Improving the prospects for student employment success in an uncertain environment. Active Learning in Higher Education, 15(3), 199-213. https://doi.org/10.1177/1469787414544875

Rajani, S.T., \& Joshua, A.J. (2016). Employee engagement: An imperative for creating job satisfaction in evolving workplaces. IOSR Journal of Business and Management, 18-21.

Raju, T., \& Prabhu, R. (2019). Business research methods. MJP Publisher

Rothmann, S., Jackson, L.T.B., \& Kruger, M.M. (2003). Burnout and job stress in a local government: The moderating effects of sense of coherence. South African Journal of Industrial Psychology, 29(4), 52-60. https://doi.org/10.4102/sajip.v29i4.122

Rothmann, S., \& Rothmann, Jr. S. (2010). Factors associated with employee engagement in South Africa. SA Journal of Industrial Psychology, 36(2), 1-12. https://doi.org/10.4102/sajip.v36i2.925

Schaufeli, W.B., \& Bakker, A.B. (2003). Utrecht work engagement scale: Preliminary manual. Utrecht: Utrecht Occupational Health Psychology Unit, Utrecht University.

Schaufeli, W.B., Leiter, M.P., \& Maslach, C. (2009). Burnout: 35 years of research and practice. Career Development International, 14(3), 204-220. https://doi org/10.1108/13620430910966406

Schaufeli, W. B., \& Taris, T. W. (2014). A critical review of the job demands-resources model: Implications for improving work and health. Bridging occupational, organizational and public health, 43-68.

Schaufeli, W.B., Taris, T.W., \& Van Rhenen, W. (2008). Workaholism, burnout, and work engagement: Three of a kind or three different kinds of employee well-being? International Association of Applied Psychology, 57(2), 173-203. https://doi. org/10.1111/j.1464-0597.2007.00285.x

Segal, B. (2009). Employee engagement masks real differences in work attitudes between whites and minorities. New York, NY: Sirota Survey Intelligence.

Shukla, S., Adhikari, B., \& Singh, V. (2015). Employee engagement-role of demographic variables and personality factors. Amity Global HRM review, 5, 65-73.

Sôderfeldt, M., Sôderfeldt, B., \& Warg, L-E. (1995). Burnout in social work. Socia Work, 40(5), 638-646.

Storm, K., \& Rothmann, S. (2003). The validation of the Utrecht work engagement scale in the South African police services. South African Journal of Industria Psychology, 29(4), 62-70. https://doi.org/10.4102/sajip.v29i4.129

Sunny, T. R., \& Joshua, A. J. (2016). Employee engagement: An imperative for creating job satisfaction in evolving workplaces. IOSR Journal of Business and Management (IOSR-JBM), 1(1), 18-21.

Tsigilis, N., Zachopoulou, E., \& Grammatikopoulos, V. (2006). Job satisfaction and burnout among Greek early educators: A comparison between public and private sector employees. Educational Research and Reviews, 1(8), 256-261.

Usman, M., \& Raja, N.S. (2013). Impact of job burnout on organizational commitment of public and private sectors: A comparative study. Middle-East Journal of Scientific Research, 18(11), 1584-1591.

Van den Broeck, A., Vansteenkiste, M., De Witte, H., \& Lens, W. (2008). Explaining the relationships between job characteristics, burnout, and engagement: The role of basic psychological need satisfaction. An International Journal of Work, Health \& Organisations, 22(3), 277-294. https://doi.org/10.1080/02678370802393672

Van der Vaart, L. (2012). Employee well-being, turnover intention and perceived employability: A psychological contract approach. Doctoral dissertation. Potchefstroom: North-West University.

Vanhercke, D., De Cuyper, N., \& De Witte, H. (2016). Perceived employability and well-being: An overview. Psihologia Resurselor Umane, 14(1), 8-18.

Vargas, R., Sánchez-Queija, M.I., Rothwell, A., \& Parra, Á. (2018). Self-perceived employability in Spain. Education + Training, 60(3), 226-237. https://doi. org/10.1108/ET-03-2017-0037

Vigoda-Gadot, E., Eldor, L., \& Schohat, L.M. (2012). Engage them to public service: Conceptualization and empirical examination of employee engagement in public administration. The American Review of Public Administration, 43(5), 518-538. administration. The American Review of Public
https://doi.org/10.1177/0275074012450943 